\title{
Interactive Effects of Exhaustive Exercise Training and Curcumin Supplementation on PDGF-BB and TGF- $\beta 1$ Gene Expressions in Alcoholic Rats
}

\author{
Hoseyn Dalvand ${ }^{1}$, Ahmad Hematfar ${ }^{2 *}$, Naser Behpoor ${ }^{3,4}$ \\ 1- Ph.D Student of Exercise Physiology, Department of Exercise Physiology, Borujerd Branch, Islamic Azad University, Borujerd, Iran. \\ 2-Assistant Professor, Department of Exercise Physiology, Borujerd Branch, Islamic Azad University,Borujerd, Iran. \\ 3-Associate Professor, Faculty of Physical Education, Razi University, Kermanshah, Iran. \\ 4-Associate Professor, Department of Exercise Physiology, Borujerd Branch, Islamic Azad University, Borujerd, Iran.
}

\section{A B S T R A C T}

Background and Objectives: Curcumin and exercise training are suggested to improve hepatic disorders. The aim of this study was to investigate effects of two weeks of swimming training and curcumin supplementation on platelet-derived growth factor (PDGF-BB) and transforming growth factor beta 1 (TGF- $\beta 1$ ) gene expressions following ethanol consumption in Wistar male rats.

Materials and Methods: Totally, 32 Wistar male rats were divided into four equal groups, including control, exercise, curcumin and curcumin-exercise groups. Ethanol was gavaged to all groups $\left(\mathrm{g} \mathrm{kg}^{-1}\right)$ for four days. Then, the renunciation period (four days) started. The exercise period included two weeks, each week included five sessions of exhaustive swimming. Curcumin supplementation $\left(50 \mathrm{mg} \mathrm{kg}^{-1}\right)$ was used with trainings.

Results: Curcumin supplementation demonstrated significant decreases in expression of PDGF-BB $(P=0.025)$ and TGF$\beta 1(P=0.033)$ genes. In exercise groups, significant decreases were seen in expression of PDGF-BB $(P=0.007)$ and TGF- $\beta 1(P=0.001)$ genes. Interaction of exercise and curcumin resulted in significant decreases in expression of PDGFBB $(P=0.040)$ and TGF- $\beta 1(P=0.013)$ genes.

Conclusions: In conclusion, expression decreases in PDGF-BB and TGF- $\beta 1$ genes suggest that exercise and curcumin consumption can protect hepatic tissues through controlling hepatic satellite cell (HSC) activation, preventing negative effects of ethanol.

Keywords: Curcumin, Exercise training, Ethanol, PDGF-BB, TGF- $\beta 1$

\section{Introduction}

Increase of high-risk behaviors such as ethanol drink in the society have been recognized as one of risk factors of many diseases, including obesity, cardiovascular diseases (CVD) and metabolic syndrome $(1,2)$. Excess use of ethanol has indirectly been described as one of the major factors of liver injuries (3-5). Ethanol exposure results in alcoholic fatty liver, inflammation, necrosis, fibrosis and cirrhosis as major reasons of mortality in developing countries (6). Role of cytokines in development of hepatic fibrosis has widely been studied. It has been reported that the most important injuries of ethanol are resulted from increases in oxidative stress and mitochondrial injury (7). Liver cytokines such as
PDGF-BB and TGF- $\beta 1$ have been studied as hepatic damage biomarkers (8). Oxidative metabolites of ethanol such as acetaldehyde are often linked to viral or metabolic hepatic diseases and are expressed as the major reason of hepatic fibrogenesis. Acetaldehyde causes injury to cellular membrane, starting lipid peroxidation and development of harmful proteins that result in activation of Kupffer cells and presinusoidal leptocytes, which lead to release of PDGF and TGF- $\beta 1$ (9). Studies have been carried out on hepatic satellite cells (HSC). It has been reported that oxidative stress includes microsomal and mitochondrial systems. Recent studies suggest that stimulation of Kupffer cells by portal vein endotoxins 
causes release of cytokines and chemokines, hepatocyte hyper-metabolism and activation of HSC. Activation of HSC is associated to increased expression of PDGF and TGF- $\beta 1$ as pathways of hepatic fibrosis and cirrhosis (10). The TGF- $\beta$ is a major regulator in chronical hepatic disease that plays roles in all stages of the disease. The PDGF is the major stimulator of HSC proliferation, migration and regulation following hepatic injuries. The main chemical subunit is PDGF-BB that plays the most important role in signaling pathways of HSC (8). Studies have shown that PDGF-BB is one of the bestknown mitogens that cause increased hepatic fibrosis through HSC activation. Furthermore, PDGF-BB is greatly expressed in liver tissues during fibrogenesis $(10,11)$.

Evidences show that appropriate physical activities include decreasing effects on ethanol exposure and injuries caused by the chemical (12). Furthermore, it has been reported that circular resistance exercises do not affect serum PDGF-BB (13). Regarding major roles of TGF- $\beta 1$ protein in creation sport exercise adaptations, effects of various exercise methods on the protein expression have been studied. The TGF$\beta 1$ has been demonstrated to increase in gastrocnemius muscles of Wistar male rats following intensive interval trainings (14). Moreover, exhaustive intensity sport activities have been shown to significantly increase serum TGF- $\beta 1$ (15). In recent years, use of plant antioxidants as non-pharmaceutical treatments in various diseases has become popular. Curcumin is a polyphenolic compound and a derivative active substance from rhizome of turmeric plants with verified antioxidant, anti-inflammatory, antimicrobial and supportive effects on hepatic cells (16-18). Curcumin may protect liver against oxidative stress resulted from ethanol use (19). Studies have shown that curcumin supplement with acupuncture cause significant decreases in PDGF-BB in rats (20). Regarding effects of curcumin, it has been reported that 8-week use of curcumin causes significant decreases in TGF- $\beta 1$ gene expression (21). In contrast, 12-week consumption of curcumin does not include significant effects on TGF- $\beta 1$ and PDGF-BB expressions (22). Data on TGF- $\beta 1$ and PDGF-BB regulations through physical exercise and curcumin use are limited and controversial. It is still unclear that who exercise training and curcumin use affect TGF$\beta 1$ and PDGF-BB in alcoholic male rats. Studies have been carried out on long-term exercise effects. Regarding controversial findings of these studies and the fact that patterns of short-term exercises are ambiguous, further studies seem necessary. Studies that simultaneously assess combinations of curcumin supplementation (low doses) with short-term exercise protocol are limited. Therefore, the present research was carried out to investigate simultaneous effects of curcumin and exhaustive swim exercise on hepatic injury biomarkers resulted from ethanol exposure in Wistar male rats.

\section{Materials and Methods}

In this study, 32 Wistar male rat, weighting $220.244 \mathrm{~g} \pm 2.32$ and aging eight-week old, were randomly divided into four equal groups, including control, exercise, curcumin supplementation and curcumin supplementation-exercise. Animal experiments were first approved by the Ethics Committee of Borujerd Branch, Islamic Azad University, Boroujerd, Iran (IR.IAU.B.REC.1396.6). A 12-h light-dark cycle was equally used for the animals. Rats were hosted in cages with temperature of $20-21^{\circ} \mathrm{C}$ and humidity of $40-60 \%$. In addition to pre and post-period weight measurements, animal weights were measured and recorded before ethanol gavages. All groups were ethanol gavaged according to standard protocols of excess ethanol consumption (3) once per $8 \mathrm{~h}$ daily as $5 \mathrm{~g} \mathrm{~kg}^{-1}$ body weight (B.W.) for four days. The greatest consumption dose included $7 \mathrm{~g} \mathrm{~kg}^{-1}$ B.W. daily. During ethanol use, rats were not fed; however, water was always available. To gavage ethanol, $25 \%(\mathrm{w} / \mathrm{v})$ ethanol in vanilla supplements (Abbot Laboratories, Columbus, OH, USA) were prepared and used in all groups according to guidelines. After four days of ethanol consumption, six days of withdrawal started and feed was provided to animals. From Day 7, interventions began in various groups. All interventions were executed in thelight phase from 9 AM to 2 PM. The exercise period included two weeks, each week included five sessions of exhaustive swimming in pool with adjustable water temperature of $20-22{ }^{\circ} \mathrm{C}$. Then, $10 \%$ curcumin (Sigma, St. Louis, Mo, USA) solutions were prepared using DMSO (Sigma, ST. Louis, MO, USA). Rats in supplement and supplement-exercise groups were injected with $50 \mathrm{mg} \mathrm{kg}^{-1}$ B.W. of curcumin for two weeks, five times a week. Similarly, swimming sessions were carried out for two weeks, five times a week. All injections were carried out at 
10-11 AM. In ethanol-exercise and ethanol-exercisecurcumin groups, swim training was carried out $2 \mathrm{~h}$ after curcumin injection.

Before dissecting, animals were fasted for $12 \mathrm{~h}$. Rats were sacrified $48 \mathrm{~h}$ after the last intervention session using ketamine (30-50 $\mathrm{mg} \mathrm{kg}^{-1}$ B.W.) and xylazine (3-5 $\mathrm{mg} \mathrm{kg}^{-1}$ B.W.). Rats were dissected and their livers were removed; then, extracted tissues were transferred into microtubes. Liver tissues were washed and stored at $-80{ }^{\circ} \mathrm{C}$ until use. To study gene expressions of PDGF-BB and TGF- $\beta 1$, real-time PCR was used (Fermentase, Germany). Total RNA was extracted and treated with DNase I (Roche, Basel, Switzerland) to remove genomic DNA contamination. The cDNA was synthesized in a total volume of $20 \mu \mathrm{l}$ using commercial kits (Fermentas, Lithuania) at 42 ${ }^{\circ} \mathrm{C}$ for $60 \mathrm{~min}$ according to the manufacturer's instructions. TaqMan real-time PCR was used for the quantification of relative gene expression using QuantiTect SYBR Green RT-PCR Kit (Takara Bio, Japan). Forward and reverse primer pairs were designed using Primer-3 Plus Software for exon-exon junctions to distinguish between cDNA and genomic DNA. The PCR primers were tested using PrimerBlast Online Tool (www.ncbi.nlm.nih.gov/tools/ primer-blast). Descriptive information were reported as mean $\pm \mathrm{SD}$ (standard deviation). In data analysis, Kolmogorov-Smirnov test was used to show data normality. Two-way analysis of variance (two- way ANOVA) was used to show interactive effects of independent variables. Moreover, post-hoc least significant difference (LSD) test was used as well as Levin test, which indicated homogeneities in variances. Data were analysis using PASW Statistic Software (Inc.c.Chicago, Illinois,USA).

\section{Results}

Kolmogorov-Smirnov test showed that data were natural (PDGF-BB gene, $P=0.987$; TGF- $\beta 1$ gene, $P=0.159)$. Levin test indicated homogeneities in variances (level of significance for PDGF-BB and TGF- $\beta 1$ were 0.516 and 0.200 , respectively). Comparison of expression changes in PDGF-BB gene in study groups are shown in Tables 1 and 2 and Fig. 1. Based on results from Table 2 and Fig. 1, exercise independently $(P=0.007$ and $\mathrm{F}=9.572)$, curcumin supplement independently $(P=0.025$ and $\mathrm{F}=6.164)$ and exercise-curcumin supplement interaction $(P=0.04$ and $\mathrm{F}=4.980)$ significantly decreased expression of PDGF-BB, compared to ethanol group. Comparisons of expression changes in TGF- $\beta 1$ gene against beta-actin in the study groups are demonstrated in Table 3 and Fig. 2. Results from Table 3 and Fig. 2 show significant decreases in expression of TGF- $\beta 1$ gene within the three groups of exercise $(P=0.001$ and $\mathrm{F}=17.713)$, curcumin supplement $(P=0.033$ and $\mathrm{F}=5.424)$ and exercisecurcumin supplement $(P=0.013$ and $\mathrm{F}=7.724)$, compared to ethanol group.

Table 1. Descriptive indices of the major studied variables $(\mathrm{X} \pm \mathrm{SD})$

\begin{tabular}{|c|c|c|c|c|c|}
\hline Variable & Group & Ethanol & Curcumin & Exercise & Exercise-curcumin \\
\hline PDGF-BB gene & & $0.0065 \pm 0.0021$ & $0.0028 \pm 0.001$ & $0.0024 \pm 0.0014$ & $0.0022 \pm 0.0019$ \\
\hline TGF- $\beta 1$ gene & & $0.0045 \pm 0.0027$ & $0.0012 \pm 0.0008$ & $0.0001 \pm 0.0001$ & $0.0003 \pm 0.0003$ \\
\hline
\end{tabular}

Table 2. Changes in PDGF-BB gene expression relative to beta-actin due to exercise, curcumin and exercise-curcumin interactions

\begin{tabular}{llllcl}
\hline Group & $\begin{array}{l}\text { Effect } \\
\text { size }\end{array}$ & F-value & $\begin{array}{l}\text { Significance level } \\
\text { of } P\end{array}$ & $\begin{array}{l}\text { Average of } \\
\text { squares }\end{array}$ & $\begin{array}{l}\text { Freedom } \\
\text { degree }\end{array}$ \\
\hline Exercise effect & 0.374 & 9.572 & 0.007 & 0.000 & 1 \\
Curcumin effect & 0.278 & 6.164 & 0.025 & 0.000 & 0.000 \\
Interactive effect of exercise and curcumin & 0.237 & 4.98 & 0.04 & 0.000 & 1 \\
& & & 0.000
\end{tabular}


Table 3. Changes in TGF- $\beta 1$ gene expression relative to beta-actin as a result of exercise, curcumin and exercise and curcumin interactions

\begin{tabular}{|c|c|c|c|c|c|c|}
\hline Group & Effect size & F-value & $\begin{array}{c}\text { Significance } \\
\text { level of } P\end{array}$ & Average of squares & $\begin{array}{c}\text { Freedom } \\
\text { degree }\end{array}$ & Total \\
\hline Exercise effect & 0.225 & 17.713 & 0.001 & 0.000 & 1 & 0.001 \\
\hline Curcumin effect & 0.253 & 5.424 & 0.033 & 0.000 & 1 & 0.000 \\
\hline Interactive effect of exercise and Curcumin & 0.326 & 7.724 & 0.013 & 0.000 & 1 & 0.000 \\
\hline
\end{tabular}

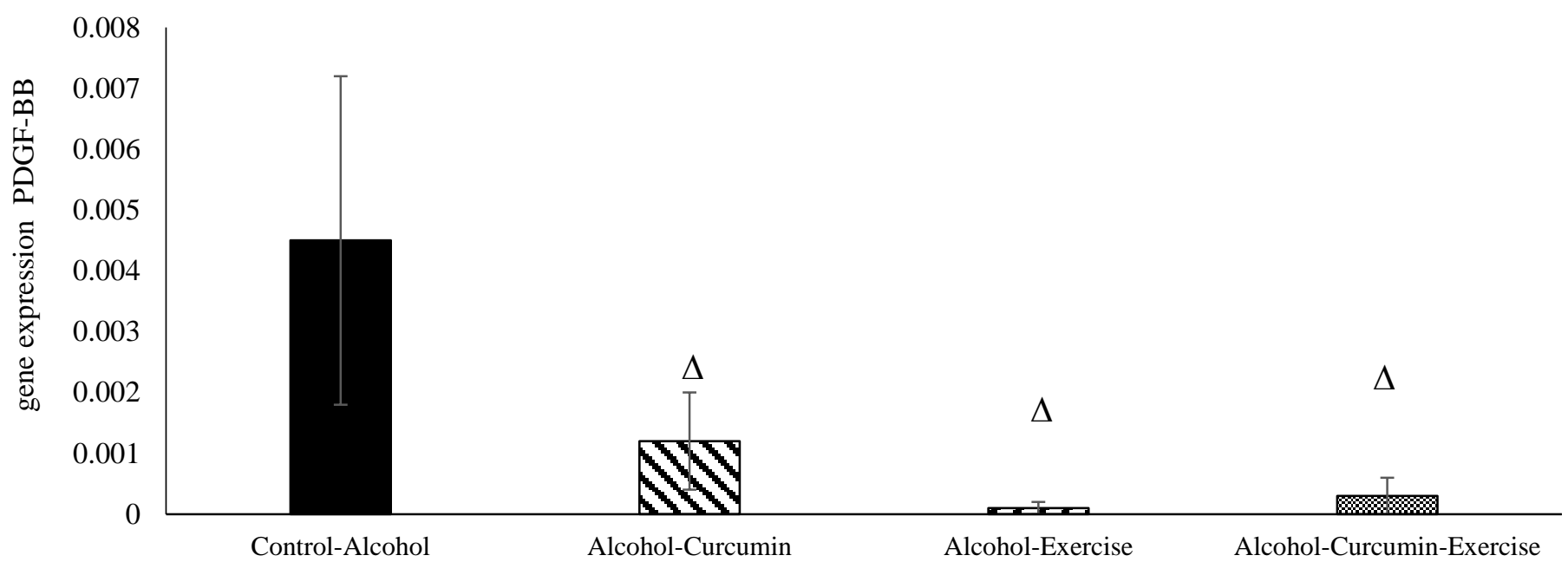

Figure 1. Changes in PDGF-BB gene expression relative to beta-actin in various research groups.

$\Delta$ indicates significant differences with control groups $(P \leq 0.05)$

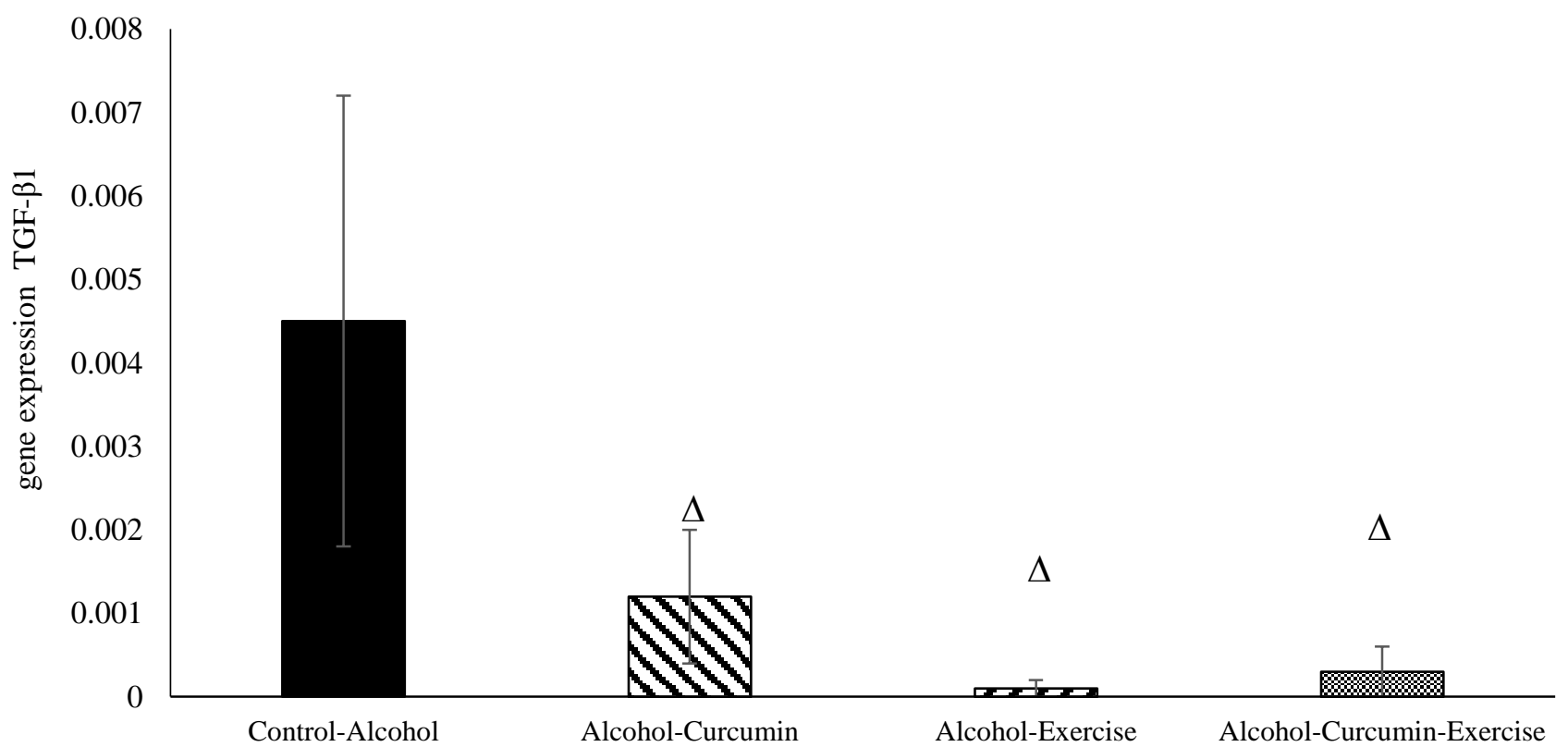

Figure 2. Changes in TGF- $\beta 1$ gene expression in various groups of the study.

$\Delta$ indicates significant differences with control groups $(P \leq 0.05)$ 


\section{Discussion}

In general, the current study has shown that curcumin supplementation, exercise and simultaneous exercise-curcumin supplement protocols can significantly decrease expression of PDGF-BB and TGF- $\beta 1$ genes and possibly improve the negative effects of ethanol on the liver and prevent development of fatty liver diseases. Fu et al. (2008) have shown that curcumin supplementation significantly decreases expression of PDGF-BB and TGF- $\beta 1$ genes and hence controls HSC activation and protects hepatic tissues against injuries. This property of curcumin may prevent negative effects of ethanol on liver and avoid increases in highlighted gene expressions (23). Curcumin possibly imposes its protective effects through removal of toxic metabolites (24), antioxidant effects and decrease of oxidative stress as well as inhibition of lipid peroxidation $(24,25)$. In the present study, exercise independently caused a significant decrease in expression of PDGF-BB gene. Berari et al. (2015) have demonstrated that circular resistance exercise does not affect serum PDGF in inactive young women (13) in contrast to the present study. This difference may be due to differences in subjects, intensities and durations and types of exercises. In the present study, curcumin supplementation independently caused a significant decrease in expression of PDGF-BB gene. Similarly, Zhang et al. (2012) have reported that curcumin and acupuncture strongly decrease PDGF in rats and stop PDGF-BR cascade of extracellular signal-regulated kinases (PDGF -BR/ERK). In fact, HSC activation results in extracellular matrix disorders. It has been verified that high levels of PDGF activate HSC. The PDGF transports its signals through PDGF receptors and cascades of mitogenactivated protein kinases (MAPK) downstream, including ERK-MAPK, JNK- MAPK (Jun aminoterminal kinase) and P38-MAPK. Therefore, decreases in PDGF can interrupt this cascade and become an effective agent for the improvement of hepatic fibrosis (20). Similar to the present study, Fu et al. (2008) have demonstrated that curcumin significantly decreases expression of PDGF-BB and TGF- $\beta 1$ genes and consequently protects liver tissues against injuries. Mitogen proliferation of PDGF and TGF- $\beta 1$ genes, majorly from Kupffer cells, activates hepatic satellite cells (HSC). This process is paired with highly continuous expression of PDGF- $\beta$ (PDGF- $\beta R$ ) receptor, called receptors Types I and II for TGF- $\beta$ (T $\beta-\mathrm{R}$ II and T $\beta-\mathrm{R}$ I). Moreover, HSC activation simultaneously occurs with significant decreases in activated $\gamma$-receptors by peroxisome proliferators (PPARy). Normally, curcumin controls HSC activity through increasing PPAR and decreasing PDGF and TGF, their receptors and collagen Type I. It has been reported that interruptions in signaling pathways of TGF- $\beta$ and PDGF by curcumin is necessary, requiring that curcumin inducts expression of PPAR gene (23). Through hepatic fibrogenesis, decreases in PPARy frequency have been linked to activation of mitogenic signaling for PDGF in HSCs cells (the major effective cells). Increases in PPARy activity by curcumin may result in stopped PDGF signaling. Curcumin has been reported to interrupt PDGF signaling, stimulate expression of PPARy gene, increase the gene activity and result in inhibited cell proliferation of active HSC. Furthermore, curcumin may block activation of ERK, JNK and PI-3K/AKT signaling pathways in passaged HSC, which verifies effects of curcumin on the interruption of PDGF and EGF signaling in HSC (26). Studies have described that curcumin inhibits PDGF using various treatment strategies. Further studies have demonstrated that the quantity of doserelated curcumin decreases expression of PDGF receptor genes such as PDGF- $\beta$ R and hence activates PPARy (27). Furthermore, curcumin decreases phosphorylation levels of PDGF- $\beta$ R and downstream signaling cascades, including ERK1/2 and JNK1/2. In general, results suggest that increased PPARy activity by curcumin interrupts signaling PDGF in activated HSC, through decreasing phosphorylation levels of PDGF- $\beta$ R and suppresses expression of the receptor genes (28).

In the present study, curcumin significantly decreased expression of TGF- $\beta 1$ gene, similar to a study by Sotikno et al., who have shown that 8 -week use of curcumin significantly decreases expression of TGF- $\beta 1$ gene. This decrease is possibly due to phosphorylation and nucleus displacement of Smad$2^{1}$ and/or inhibition of receptors Type I and II and TGF- $\beta 1$ (21). The interactive effects of TGF- $\beta 1$ and their membrane receptors result in phosphorylation of

\footnotetext{
${ }^{1}$ Small mothers against decapentaplegic: including a family of structurally similar proteins as the major signal transducers for the receptors of transforming growth factor beta (TGF-B) superfamily, critically important for the regulation of cell development and growth.
} 
intra-cellular intermediates of Smad proteins, which act as transcription factors in nucleus and cell proliferation processes. The Smad-TGF- $\beta 1$ complex is a major profibrogenic pathway. Modulation of expression and interaction of TGF- $\beta 1$ and their receptors is resulted from curcumin use (27). Curcumin has been reported to ameliorate cirrhosis resulted from blocking bilious ducts through lowregulation of TGF- $\beta$ and inhibition of oxidative stress. Indeed, curcumin inhibits highly regulation of protein expression of TGF- $\beta 1$ mRNA and TGF- $\beta$ in rat hepatic tissues with blocked bilious ducts. The preventative role of curcumin against fibrosis resulted from bilious cirrhosis has been attributed to the chemical antioxidant effects (29). Brocko et al. (2007) have studied effects of daily curcumin use of $33 \mathrm{mg}$ $\mathrm{kg}^{-1}$ on protection of liver in rats for 12 weeks and shown that curcumin does not significantly affect expression of TGF- $\beta 1$ and PDGF; in contrast to the present study (22). However, results of the current study are similar to those of Sotincko et al. (2011) study, which shows that 8-week use of curcumin in diabetic rats significantly decreases expression of TGF- $\beta 1$. A part of this decrease is likely due to inhibition of macrophage infiltration mediated by inflammatory response of NF-kB (21). Significant decreases in TGF- $\beta$ gene expression due to swimming exercises are similar to those of a study by Doustar et al. (2009). They have suggested that after two weeks of exercises (five sessions a week, each session consists of 1-h exercise on treadmill), expression of TGF- $\beta$ in exercise group significantly decreases. Sport activities can prevent proliferation of myofibroblasts through increasing insulin sensitivity and hypoglycemia induction and hence TGF- $\beta$ production and collagens 1 and 4 inhibition. The TGF- $\beta$ factor includes important roles in diabetic nephropathy. Hyperglycemia is one of the most important factors inducting TGF- $\beta$ production from mesenchymal cells. High blood sugar levels stimulate proliferation of mesenchymal cells and myofibroblasts and therefore high levels of collagens 1 and 4 and TGF- $\beta$ are produced. However, sport activities can prevent proliferation of mesenchymal cells through increasing insulin sensitivity and hypoglycemia induction and thereby inhibiting production of TGF- $\beta$ and collagens 1 and 4 . It is certainly known that exercises by controlling blood sugar inhibit production of TGF- $\beta$ and decrease fibrosis of liver tissues. This can also justify significant differences between control and exercise groups for decreasing pathologic changes following exercises. Furthermore, oxidative stresses, as inductive agents of cell injuries in diabetic patients suffering from nephropathy, decrease following exercises (30).

Studies have demonstrated that eight weeks of swimming exercises do not change TGF- $\beta$ levels in healthy rats; contrary to the present study (31). The previous exercise protocol for the induction of diabetic conditions started with 5 min of swimming at the first week and increased to $30 \mathrm{~min}$ at the third week; then, continued for eight weeks. It seems that the highlighted exercise protocol cannot induce sufficient adaptations to change the indices in healthy rats; possibly due to insufficient severity and duration of exercises (31). Studies have shown that TGF- $\beta$ signaling pathways initiate with stimulations of Smad-2 and Smad-3 and are phosphorylated and activated under the effects of Smad-4 via serinethreonine receptors of kinases connected to cellular membranes. The latter protein enters the nucleus with other members of the Smad protein family in forms of homological and non-homological compounds and initiates processes of preventing cell differentiation and controlling cell growth. The major target of TGF$\beta /$ Smad-3 is to prevent the processes of cell proliferation and growth (32, 33). Therefore, increases in TGF- $\beta /$ Smad-3 expression due to endurance trainings can increase inhibitory effects of this pathway and prevent cellular differentiation and tumor growth (34). Moreover, it is clear that exhaustive intense sport activities significantly increase serum levels of TGF- $\beta$ (15). Reasons for TGF- $\beta 1$ increase are not clearly explained; however, oxidative stress and hypoxia resulted from exercises are two possible mechanisms that may explain increases of this factor following exercises (35). Curcumin and sport exercises may obviously decrease hepatic injuries due to ethanol use through increasing antioxidant activities. Furthermore, curcumin supplementation maintains beneficial effects of exercises on biochemistry of hepatic factors (35). Results of the present study have clarified that two weeks of swimming exercises to exhaustion, curcumin supplementation and exercise and curcumin supplement interaction significantly decrease expressions of PDGF and TGF- $\beta 1$. Therefore, 
interaction of endurance sport activity and curcumin use can be considered as a relatively appropriate method to heal hepatic injuries due to ethanol use. Nevertheless, longer periods of sport interventions and curcumin use are needed to increase effects of exercise and curcumin as well as complete ethanol withdraw. It is noteworthy that exhaustive physical activities alone can release free radicals and increase oxidative pressures (36). However, adaptability with exercises can improve the highlighted variables even in short periods.

\section{Acknowledgement}

This article was extracted from a PhD thesis. The study was carried out at the Department of Exercise Physiology, Borujerd Branch, Islamic Azad University, Borujerd, Iran (Registration No. 1396.6).

\section{Financial disclosure}

Authors declare no conflicts of interest.

\section{References}

1. Martins IS, Coelho LT, Casajus MI, Okani ET. Smoking, consumption of alcohol and sedentary life style in population grouping and their relationships with lipemic disorders. Revista de saude publica. 1995;29(1):38-45.

2. Mokdad AH, Marks JS, Stroup DF, Gerberding JL. Actual causes of death in the United States, 2000. Jama. 2004;291(10):1238-45.

3. Maynard ME, Leasure JL. Exercise enhances hippocampal recovery following binge ethanol exposure. PloS one. 2013;8(9):e76644.

4. Mokdad AA, Lopez AD, Shahraz S, Lozano R, Mokdad AH, Stanaway J, et al. Liver cirrhosis mortality in 187 countries between 1980 and 2010: a systematic analysis. BMC medicine. 2014;12:145.

5. Ponomarenko Y, Leo MA, Kroll W, Lieber CS. Effects of alcohol consumption on eight circulating markers of liver fibrosis. Alcohol and alcoholism. 2002;37(3):2525 .

6. Varatharajalu R, Garige M, Leckey LC, Reyes-Gordillo K, Shah R, Lakshman MR. Protective Role of Dietary Curcumin in the Prevention of the Oxidative Stress Induced by Chronic Alcohol with respect to Hepatic Injury and Antiatherogenic Markers. Oxidative medicine and cellular longevity. 2016;2016:5017460.

7. Song BJ, Akbar M, Abdelmegeed MA, Byun K, Lee B, Yoon SK, et al. Mitochondrial dysfunction and tissue injury by alcohol, high fat, nonalcoholic substances and pathological conditions through post-translational protein modifications. Redox biology. 2014;3:109-23.
8. Grigorescu M. Noninvasive biochemical markers of liver fibrosis. Journal of gastrointestinal and liver diseases : JGLD. 2006;15(2):149-59.

9. Schuppan D, Atkinson J, Ruehl M, Riecken EO. Alcohol and liver fibrosis--pathobiochemistry and treatment. Zeitschrift fur Gastroenterologie. 1995;33(9):546-50.

10. Crabb DW. Pathogenesis of alcoholic liver disease: newer mechanisms of injury. The Keio journal of medicine. 1999;48(4):184-8.

11. Zhou J, Deng Y, Yan L, Zhao H, Wang G, China Hep BRFARG. Serum platelet-derived growth factor BB levels: a potential biomarker for the assessment of liver fibrosis in patients with chronic hepatitis B. International journal of infectious diseases : IJID : official publication of the International Society for Infectious Diseases. 2016;49:94-9.

12. Georgakouli K, Manthou E, Fatouros IG, Deli CK, Spandidos DA, Tsatsakis AM, et al. Effects of acute exercise on liver function and blood redox status in heavy drinkers. Experimental and therapeutic medicine. 2015;10(6):2015-22.

13. Barari A, Bashiri J, Sarabandi M. The Effect of Circuit Resistance Training Combined with Ginseng Supplementation Level of VEGF and PDGF in Inactive Females. Medical Journal of Tabriz University of Medical Sciences and Health Services. 2015;37(5):613.

14. Nikooie R, Sajadian S. TGF- $\beta 1$ protein Expression in the Skeletal Muscle Following High Interval Training and its Relationship with Intramuscular Triglycerides Oxidation. JOURNAL OF SPORT IN BIOMOTOR SCIENCES. 2015;6(12):45-54

15. Borujeny AK, Marandi M, Javanmard SH, Rajabi H, Burojeny ZK, Behzadi MK. Effect of Eight Weeks of Resistance Training on Some Signaling Factors Affecting on the Satellite Cells in Wistar Rats. Journal of Isfahan Medical School. 2012;30((207): 1500-11

16. Garcia-Nino WR, Pedraza-Chaverri J. Protective effect of curcumin against heavy metals-induced liver damage. Food and chemical toxicology : an international journal published for the British Industrial Biological Research Association. 2014;69:182-201.

17. Nanji AA, Jokelainen K, Tipoe GL, Rahemtulla A, Thomas P, Dannenberg AJ. Curcumin prevents alcoholinduced liver disease in rats by inhibiting the expression of NF-kappa B-dependent genes. American journal of physiology Gastrointestinal and liver physiology. 2003;284(2):G321-7.

18. Varatharajalu R, Garige M, Leckey LC, Reyes-G K, Shah R, Lakshman MR. Protective role of dietary curcumin in the prevention of the oxidative stress induced by chronic alcohol with respect to hepatic injury and antiatherogenic markers. Oxidative medicine and cellular longevity. 2016;2016 : 1942-0900. 
19. Pyun CW, Han KH, Hong GE, Lee CH. Effect of curcumin on the increase in hepatic or brain phosphatidylcholine hydroperoxide levels in mice after consumption of excessive alcohol. BioMed research international. 2013;2013:242671.

20.Zhang XP, Zhang F, Zhang ZL, Ma J, Kong DS, Ni GX, et al. Acupuncture combined with curcumin disrupts platelet-derived growth factor beta receptor/extracellular signal-regulated kinase signalling and stimulates extracellular matrix degradation in carbon tetrachloride-induced hepatic fibrosis in rats. Acupuncture in medicine : journal of the British Medical Acupuncture Society. 2012;30(4):324-30.

21. Soetikno V, Sari FR, Veeraveedu PT, Thandavarayan RA, Harima M, Sukumaran V, et al. Curcumin ameliorates macrophage infiltration by inhibiting NFkappaB activation and proinflammatory cytokines in streptozotocin induced-diabetic nephropathy. Nutrition \& metabolism. 2011;8(1):35.

22. Bruck R, Ashkenazi M, Weiss S, Goldiner I, Shapiro H, Aeed $\mathrm{H}$, et al. Prevention of liver cirrhosis in rats by curcumin. Liver International. 2007;27(3):373-83

23. Fu Y, Zheng S, Lin J, Ryerse J, Chen A. Curcumin protects the rat liver from $\mathrm{CCl} 4$-caused injury and fibrogenesis by attenuating oxidative stress and suppressing inflammation. Molecular pharmacology. 2008;73(2):399-409.

24. Deshpande UR, Gadre SG, Raste AS, Pillai D, Bhide SV, Samuel AM. Protective effect of turmeric (Curcuma longa L.) extract on carbon tetrachlorideinduced liver damage in rats. Indian journal of experimental biology. 1998;36(6):573-7.

25. Salahshoor M, Mohamadian S, Kakabaraei S, Roshankhah S, Jalili C. Curcumin improves liver damage in male mice exposed to nicotine. Journal of traditional and complementary medicine. 2016;6(2):176-83.

26. Zhou Y, Zheng S, Lin J, Zhang QJ, Chen A. The interruption of the PDGF and EGF signaling pathways by curcumin stimulates gene expression of PPARgamma in rat activated hepatic stellate cell in vitro. Laboratory investigation; a journal of technical methods and pathology. 2007;87(5):488-98.

27. Stankovic V, Mihailovic V, Mitrovic S, Jurisic V. Protective and therapeutic possibility of medical herbs for liver cirrhosis. Romanian journal of morphology and embryology $=$ Revue roumaine de morphologie et embryologie. 2017;58(3):723-9.

28. Lin J, Chen A. Activation of peroxisome proliferatoractivated receptor-gamma by curcumin blocks the signaling pathways for PDGF and EGF in hepatic stellate cells. Laboratory investigation; a journal of technical methods and pathology. 2008;88(5):529-40.

29. Nabavi SF, Daglia M, Moghaddam AH, Habtemariam S, Nabavi SM. Curcumin and liver disease: from chemistry to medicine. Comprehensive Reviews in Food Science and Food Safety. 2014;13(1):62-77

30. Doustar Y, Mohammadi M, Mohajeri D, Hashemi M. The effect of treadmill exercise on experimental diabetic hepatopathy in rats. MEDICAL SCIENCES JOURNAL. 2009;19:17-24

31. Habibian M, Khosravi M. THE EFFECT OF 8 WEEKS REGULAR SWIMMING EXERCISE ON THE CARDIAC LEVELS OF MATRIX METTALOPROTEINASE-2 AND TRANSFORMING GROWTH FACTOR-B1 IN DIABETIC RATS. Iranian Journal of Diabetes and Lipid Disorders. 2016;15:6774.

32. Moustakas A, Souchelnytskyi S, Heldin CH. Smad regulation in TGF-beta signal transduction. Journal of cell science. 2001;114(Pt 24):4359-69.

33. Wrana JL. TGF-beta receptors and signalling mechanisms. Mineral and electrolyte metabolism. 1998;24(2-3):120-30.

34. Moghadam V, Piri M, Azarbayjani MA, Matin Homaee $H$. The protective effect of aerobic exercise on breast cancer by TGF $\beta$ protein and Smad-3 and MMP2 gene in female mice. Scientific Journal of Kurdistan University of Medical Sciences. 2017;22:60-73

35. Huang WC, Chiu WC, Chuang HL, Tang DW, Lee ZM, Wei L, et al. Effect of curcumin supplementation on physiological fatigue and physical performance in mice. Nutrients. 2015;7(2):905-21.

36. Morales-Alamo D, Calbet JA. Free radicals and sprint exercise in humans. Free radical research. 2014;48(1):30-42. 